\title{
DESPUÉS DEL FIN: LA HISTORIETA DE CIENCIA FICCIÓN EN EL PERÚ1
}

\author{
POR \\ ELTON HONORES \\ Universidad Nacional Mayor de San Marcos
}

Si bien los estudios académicos sobre la ciencia ficción en el Perú son casi nulos, mucho más marginal es el estudio de la historieta de ciencia ficción. ${ }^{2}$ El principal referente es Supercholo, apoyado sobre la base del poder simbólico del diario El Comercio de Lima, y su periodicidad, que la convirtieron en la historieta peruana más longeva, que atravesó por tres periodos: 1957-1966, 1985-1989 y 1995-1998, que suman cerca de dieciséis años de esta historieta semanal. El otro gran paradigma es la revista Avanzada (1953-1968), revista mensual que llegó a editar ciento noventa números y que incluyó varias series de ciencia ficción. A diferencia de El comercio, que puede ser consultada en diversas bibliotecas de Lima, ello no ocurre con Avanzada y con casi todas las otras revistas en papel, ya que mucho de ese material se consideró deleznable, y el Estado, desde la Biblioteca Nacional del Perú no impulsó la creación de una colección de historietas, sino todo lo contrario (durante el Gobierno Militar, se consideraba esta producción como alienante y se evitó su acopio) e incluso el coleccionismo es aún una actividad relativamente reciente y hermética. Es por ello que la principal dificultad es acceder a estas fuentes.

1 Esta investigación corresponde al capítulo cuatro de mi tesis doctoral "La ciencia ficción en el Perú", en proceso de sustentación en la Universidad Nacional Mayor de San Marcos.

2 Para delimitar el corpus definimos como ciencia ficción, aquellos relatos, narraciones en donde hay una proyección del futuro, una representación del mundo futuro en distintos niveles (socioeconómico, ético, político, científico). Los elementos básicos son: a) la inestabilidad cronológica (es decir, el uso estético del tiempo que cuestiona nuestro presente, representado popularmente en el viaje al futuro, pero también en el viaje al pasado, al mundo primitivo); b) la representación de la alteridad social y el encuentro con lo otro (universos paralelos, otros mundos, presencia de seres extraterrestres o alienígenas); c) la presencia de la ciencia como un posible elemento articulador del relato, que permite verificar un desarrollo tecnológico aplicado a la vida humana cotidiana. Estos tres elementos están implícitos en muchos relatos de ciencia ficción, pero la inestabilidad cronológica y el elemento científico son persistentes. En cuanto al mundo representado, no se trata de relatos de lo maravilloso -como sostiene Todorov-, sino que parten de un marco contextual realista, es decir, de nuestro propio mundo, con nuestras leyes naturales, reglas y regularidades. 
Será en los años cincuenta cuando empiece a aparecer de manera más consistente y con mayor regularidad una historieta de ciencia ficción en Avanzada. ${ }^{3}$ Esta década es considerada como la Edad de Oro de la historieta peruana, ${ }^{4}$ la ciencia ficción irrumpe en la cultura popular y se consolida tardíamente en la narrativa en los años setenta. ${ }^{5}$

María Regina Saraiva Mendes en El papel educativo de los comics infantiles (1991) señala algo importante: "La recesión y la depresión de la economía norteamericana generaron un ciclo de ciencia-ficción (Buck Rogers, Flash Gordon, etc.). Los héroes publicados entre 1929 y 1945 nos muestran que ellos desempeñaron un papel compensador en las crisis por las cuales pasaba el país" (40). Es decir, la angustia y el miedo colectivo encuentran su válvula de escape en el ideal del superhéroe que los representa simbólicamente y encarna así, los deseos colectivos, en épocas de crisis. Como agrega James Kakalios en La física de los superhéroes: "La creación de un superhéroe es un modo de vincular la ansiedad cultural del momento” (28). Entonces ¿Fueron los años cincuenta y setenta períodos de crisis y de ahí la necesidad de construir héroes masivos que lucharan simbólicamente contra los regímenes militares (Odría, Velasco, Morales Bermúdez)?, ¿son estos, instrumentos para deslizar críticas al sistema social?

A pesar de la clara distinción que realiza María Regina Saraiva Mendes (28-29) entre el comic tradicional, caracterizado por mantener un código ideológico conservador, visión de mundo y sistema de valores dominantes; y el comic crítico que expresa una perspectiva aguda hacia distintos aspectos de la sociedad (como el comic en Cuba o la producida en Nicaragua sandinista), consideramos que si bien en términos generales estas historietas se insertan dentro del comic tradicional, también refractan de manera soterrada ciertas tensiones, específicamente frente al orden político; el contexto sociohistórico mundial, como la Guerra Fría; además de transmitir valores, ideología, deseos y miedos de la sociedad.

3 El antecedente más antiguo de la historieta de ciencia ficción peruana sería "Viaje subterráneo" de Eduardo Calvo, publicado en la revista Palomilla (1940-1942), otra publicación mítica e inhallable. La referencia la da Carla Sagástegui, y se trataría de una historia que toma como modelo Viaje al centro de la tierra de Verne.

4 El 12 de septiembre de 1952, el diario Última Hora reemplazó las historietas extranjeras por producciones peruanas, surgiendo tiras como Boquellanta de Hernán Bartra, Juan Santos de Rubén Osorio, Sampietri de Julio Fairlie y Serrucho de David Málaga.

5 El escritor Daniel Salvo denomina como "Edad de Oro" de la ciencia ficción peruana al período que coincidiría con el Gobierno Militar (1968-1980), que incluye principalmente la obra narrativa de José B. Adolph, Juan Rivera Saavedra y José Estremadoyro. Evidentemente, esta es una posición que obvia por desconocimiento la producción historietística de los años cincuenta o en su defecto, considera implícitamente que sólo la ciencia ficción es prestigiosa si llega a adquirir una forma literaria, lo cual sería un error. Observamos entonces que este periodo (1968-1980) es más bien un periodo de consolidación de estas mismas formas, un segundo momento, respecto de esta eclosión y asimilación de la ciencia ficción que se da en los años cincuenta a través de la cultura de masas. 


\section{JuAN RuBÉN OSORIO BLANCO Y LA HISTORIETA DE CIENCIA FICCIÓN}

Juan Rubén Osorio Blanco (Jauja, 1931) es el autor de historietas más importante del Perú junto con Hernán Bartra (Iquitos, 1932), no sólo por la creación de personajes que perviven en el imaginario popular sino además por su amplia trayectoria en el medio, además de su labor en los Estudios Osito-Monky, de donde salieron muchos de los dibujantes posteriores. Ambos fueron también los directores artísticos la mítica revista de historietas Avanzada (1953-1968), dirigida por el sacerdote Ricardo Flórez Durand (1917-2004), que se vio interrumpida en sus 190 números por el golpe militar del 68. La importancia de Osorio se debe a su trabajo con los géneros de masas, en especial, con la ciencia ficción. Su primer trabajo fue "Los invasores electrónicos", publicado en tres entregas en la revista Canillita (1950) dirigida por Carlos Roose (Trujillo, 1929) conocido como Crosse. ${ }^{6}$ Ya en esta entrega inicial, aparece el tópico de la “invasión” que será reiterativo en sus trabajos posteriores de historieta seria. Uno de sus trabajos emblemáticos es La cadena de oro (1952-1956), historieta peruana publicada en el diario Última Hora desde el 12 de septiembre de 1952, junto a otras tiras locales que desplazaron a las historietas extranjeras. La cadena de oro estaba ambientada en un espacio de la sierra y el personaje principal, Juan Santos, poseía los rasgos del hombre andino, (vestía con poncho y chullo), cuya única arma -además de su fuerza física telúrica- era justamente su cadena de oro, con la que combatía a los criminales. Muchas de sus series en La cadena de oro utilizaban con frecuencia el terror, el horror, el policial, con las naturales dosis de misterio y suspenso de estos géneros de masas, pero siempre desde un registro realista, verosímil. El terror era provocado por agentes humanos, nunca sobrenaturales.

La periodicidad era diaria (de lunes a sábado), aunque la serie se descontinuaba, ya sea porque el diario no salía un día en particular o simplemente la tira tardaba en reaparecer. La importancia de Juan Santos radica en ser el primer superhéroe peruano; además de servir de modelo al Supercholo de Víctor Honigman (1921-1994) -Diodoros Kronos, seudónimo de Francisco Miro Quesada (1918) durante 1957-1966 en El Comercio. Pero si Supercholo era presentado con rasgos psicológicos ingenuos, físicamente caricaturizado, con valores positivos (inocencia, bondad, justicia) y se

\footnotetext{
${ }^{6}$ Sobre el particular, Osorio señala que: "Se trataba de una civilización que vivía en un electrón, que era parte de un átomo. Y ese universo estaba metido dentro de una piedra. Cuando los habitantes de ese planeta, de ese átomo, inventaron un aparato para hacer crecer al tamaño que ellos quisieran, construyeron un cohete y salieron del átomo, de la piedra -porque la piedra está compuesto de átomossalieron y comenzaron a agrandarse hasta el tamaño normal de los habitantes de la tierra y quisieron trasladar toda su raza a la tierra... Los mandatarios de acá de la tierra quisieron destruirlos a ellos y como tenían una ciencia muy avanzada cubrieron con una capa especial la nave donde vinieron ellos y ningún proyectil, ninguna bomba podía penetrar. Tuvieron que llegar a un acuerdo con los habitantes de la tierra y aceptaron que trasladen toda su civilización a la tierra [...]" (Honores, "Entrevista a Rubén Osorio").
} 
caracterizaba por ser un personaje más humorístico (sobre todo en sus primera entregas), Juan Santos era un héroe más serio, analítico, quien no sólo aprovecha su fuerza sino también su intelecto en la investigación. ${ }^{7}$ De más está decir que La cadena de oro era una historieta seria de aventuras.

\subsection{Ciencia ficción en La cadena de oro (1954)}

Si bien la historieta era netamente andina, en 1954 incursiona en la ciencia ficción, lo que deja en claro la gran popularidad que gozaba el género. Pero no lo hace abierta o directamente sino a través de un juego metatextual en que se observa el carácter ficcional de la tira de historieta y su relación con el autor real (Rubén Osorio), que se ve autorepresentado. Este juego, propio del posmodernismo, será común en la historieta de ciencia ficción peruana, pues aparece en Zarkhan y en algún episodio de Supercholo.

En este episodio en particular, el narrador, en una voz en off, se dirige al lector y le informa de lo que le ocurrió. Esta primera tira no posee título como en aventuras anteriores, en donde se anunciaba previamente la nueva serie de Juan Santos, sino que directamente pasamos a la anécdota. Los primeros cuadros serán de intriga. Desde el ojo de la cerradura se observa al dibujante Rubén Osorio en su tablero de trabajo, en la segunda viñeta vemos aparecer a un extraño ser alienígena, anunciado ya en la primera viñeta mediante su extraña mano, en la última viñeta el alienígena dice: “¡Quédese quieto si no lo quiere pasar mal!’. Esta afirmación no es más que una amenaza que deja en suspenso a la tira y al lector, recurso frecuente teniendo en cuenta que la tira era diaria y al autor real debía "enganchar" al lector siempre con una nueva entrega de la serie. Pero, lo que parecía ser un ente alienígena no es otra cosa que un humano disfrazado. El dibujante se mostrará siempre escéptico desde el inicio a la posibilidad real de presencia alienígena, piensa que debe ser una broma. El supuesto alienígena no es sino un guionista que viene a ofrecer una historia impactante para La cadena de oro. El dibujante considera que ya se ha escrito demasiado sobre extraterrestres y platillos voladores, pero accede a escucharle. A partir de aquí, en la narración se irán intercalando el tiempo real del dibujante con el guionista y las secuencias imaginadas propuestas por el guionistas, que dominarán este episodio. Podemos añadir que el género de ciencia ficción "invade" la tira de carácter andino. Sobre este punto bien podríamos especular que así como los años cincuenta significaron una modernización de la narrativa peruana, que dejó atrás al indigenismo dominante de los años treinta y cuarenta, aquí la referencia a la ciencia ficción cumple igual función: no hay posibilidad de construir un

7 Melvin Ledgard describe a Juan Santos como un personaje con “[...]psicología poco elaborada [y seguía] el molde de un superhéroe programado [...]" (13). 
personaje andino puro debido a los procesos de modernización, lo que implicaba a su vez, insertarlo en la cultura de masas, como también ocurre con Supercholo.

Pasando al relato enmarcado (lo que cuenta el guionista al dibujante Ruben Osorio), un brazo metálico de un platillo volador rapta a un hombre del ande, hecho que es observado por su propio hijo. Este dará aviso a las autoridades y a Juan Santos, quien va al lugar y verfica la presencia alienígena. Unas pinzas de metal descienden del platillo volador e intentan capturar a Juan Santos, pero este logra partir en dos el brazo metálico gracias a su cadena de oro, tras lo cual, la nave desaparece. En el mismo lugar conoce a Alfredo Gutiérrez, miembro del Centro de Investigaciones Interplanetarias. Él está convencido de que se trata de extraterrestres y le informa Juan Santos que según sus investigaciones, ellos tienen un plan prefijado para visitarnos. Según sus coordenadas, viajan a Tayamarca (ubicada en la provincia de Yauyos), para avistarlos nuevamente. Efectivamente, avistan nuevamente a los ovnis. De una nave se abre una escotilla. En su deseo de capturar imágenes fotográficas el profesor Alfredo resbala. Al intentar evitar que sea visto por los invasores, Juan Santos es absorbido por una cortina de luz de la nave.

Dentro de la nave, los extraterrestres se revelan a Juan Santos como provenientes de Marte. Afirman que visitan la tierra en un plan de investigación, pero luego confiesan que finalmente deben ocupar todo el planeta pues Marte está en extinción y amenaza a su raza. Justifican que su raza es superior a la humana y deben sobrevivir, por la tanto, nosostros estamos condenados a la extinción -el espacio territorial es la clave del problema, el objeto precioso de deseo, para los “desplazados" espaciales-. Allí también descubre que ellos usan los cuerpos humanos para comunicarse. Este elemento es similar al filme clásico de ciencia ficción La invasión de los ladrones de cuerpos (Invasion of the Body Snatchers, 1955) de Don Siegel (1912-1991). Ellos han raptado a otros humanos para obtener información sobre el planeta. Proponen a Juan Santos ser su aliado en la invasión, ya que han visto su poder con la cadena de oro, objeto que es retenido por los invasores. Así, retornan a la tierra y dejan a Juan Santos en la región de "Tayacacha", cerca de Tacna. El profesor Alfredo viaja al lugar y se reencuentra con Juan Santos, quien le informa sobre los planes de invasión de los marcianos y la amenaza de exterminio de los humanos. Juan Santos pide al profesor Alfredo que viaje a Lima e informe al Ministerio de Guerra. Al enterarse de la traición de Santos, los extraterrestres deciden atacar.

Lo que viene a continuación es sólo el horror de la destrucción. Todos los habitantes de la comunidad aludida - en la que se encuentra el propio Juan Santos-son exterminados, mediante unos poderosos rayos que salen de las naves invasoras. El profesor Alfredo, Adriana (amiga de Santos) y el piloto al llegar al lugar encuentran muerto a Juan Santos. Lo peor viene cuando ellos también son arrasados por los rayos invasores.

En las dos últimas tiras volvemos a la escena inicial del dibujante Rubén Osorio en su estudio y el aspirante a guionista. Este le informa que con la apararición del alienígena acaba esta historia. El dibujante cuestiona el final apocalíptico, pues con Juan Santos 


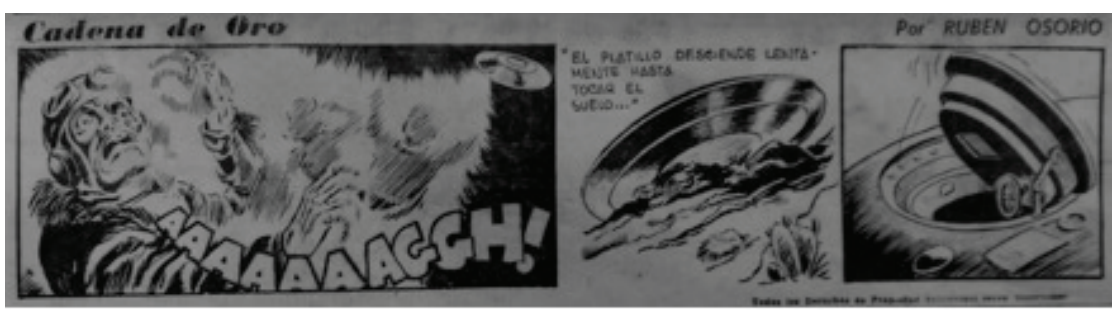

muerto, su amiga Adriana y la cadena de oro en manos alienígenas, “¿Qué aventura piensa que voy a ofrecer a los lectores?", añade al dibujante. Nos encontramos acá con una clara conciencia del género de aventuras: el héroe no puede morir ni ser derrotado, porque simplemente acabaría con la historia. Por otro lado, al partir de esta premisa, todas las aventuras de Juan Santos se construyen como artificios, en el que lo que más importa no es develar al criminal o encontrar al culpable, sino el cómo se presenta o dilata la historia, qué recursos emplea el guionista para mantener en suspenso al lector.

En la última tira se ironiza doblemente pues el dibujante Rubén Osorio -alter ego del autor real que tiene su mismo nombre- le señala al guionista que "[...] su argumento no está de acuerdo con la finalidad de esta tira y no podré aceptarlo. Quizá si escribe sobre otro tema de ambiente serrano pueda publicarlo". Aquí se grafica la línea estético-ideológica de la revista. La última frase del dibujante antes de dar el portazo es "Si lo publica lo demandaré...", lo que constituye una paradoja, ya que no se llega a publicar como episodio en sí, sino como relato enmarcado. Esto nos lleva a pensar en ciertas tensiones entre la representación mimético-verosímil dominante y los códigos de la imaginación anticipatoria (la ciencia ficción) que empieza a interferir e "invadir" el discurso realista, es decir, la ciencia ficción es posible siempre que se produzca un retorno a la realidad, su carácter o naturaleza no es evasiva.

\section{NovaC De JoRge BernuY}

Admirador de Alex Raymond (1909-1956) y Al Williamson (1931-2010), ${ }^{8}$ Jorge Bernuy Supo (Lima, 1948-México, 2000) es otro de los dibujantes peruanos que desarrolló su carrera desde los años setenta, para luego emigrar como muchos otros a México. Recordado por Yahuar, el guerrero, para el suplemento El tío Carlitos de la revista $X$, en 1976, o las ilustraciones para la revista esotérica y de ciencia ficción peruana Lo insólito (1977-1980) que llegó a editar cincuenta números, Bernuy tuvo una importante labor en los medios publicitarios y periodísticos. ${ }^{9}$ En la revista 7 Días

Consúltese Lambiek Comiclopedia. En: <http://www.lambiek.net/artists/b/bernuy_jorge.htm>

9 Martín Isla señala: “[...] Desde muy joven colabora como ayudante en algunos medios, pero fue bajo la batuta del dibujante Ricardo Villamonte, reconocido ilustrador de Expreso por esos años, con quien 
del Perú y del Mundo, Bernuy "[...] ilustraba varios reportajes policiales, de ciencia ficción, dramáticos, y la enciclopedia infantil 'Cococraneo' [...]" (Franco). ${ }^{10}$ A fines de los setenta viaja a México para mejorar su situación económica y se hace cargo de la serie Tarzán (1979-1982) de la editorial mexicana Novaro y colabora en otras publicaciones del medio hasta su muerte.

Novac se publicó entre 1973 y 1974 en el suplemento de historietas del diario limeño La prensa. Sobre esta, Melvin Ledgard sentencia que era "[... una historieta de ciencia ficción de tan poca originalidad como la idea de enfundar a un héroe del futuro en una malla ceñida a su anatomía" (52). La descripción es superficial y negativa, pues en un medio en el que la historieta de ciencia ficción es marginal, e incluso el soporte periodístico fue lo más cercano a una industria editorial historietística, un juicio así niega su valor a esta producción y la condena al olvido inmediato. Más aún porque o se sigue pensando en el modelo norteamericano de comics (Superman, Batman, Spiderman) como superior o se considera que la historieta peruana -al igual que la tradición literaria peruana- tiene una clave realista dominante y que por lo tanto es relevante aquella que utiliza una representación mimético-verosímil. Si bien no encontraremos en Novac alusiones directas al Perú, como todo objeto artístico refracta tensiones reales de la sociedad y transmite valores aceptados socialmente, al igual que una ideología: no están construidos en el aire ni se sostienen en la pura fantasía.

Las primeras imágenes de Novac presentan al personaje enfundado en mallas. Las referencias visuales son Flash Gordon, Conan, el bárbaro e incluso Tarzán. Una nave surca el espacio. La misión de Novac es la de explorar nuevos planetas para aumentar el archivo espacial, es decir, hay una pretensión enciclopédica y racionalista. El planeta al que llega el héroe contiene elementos radioactivos como consecuencia de una guerra atómica. Esta situación refracta la posibilidad real de destrucción del planeta tierra, recoge el miedo y ansiedad social luego de la posguerra. Indirectamente se desliza la idea que así como este planeta llegó a su fin mediante la autodestrucción, otros también

se inicia profesionalmente en 'Protzel Publicidad', una prestigiosa agencia limeña a inicios de los 70 en donde aprende a bocetar, diagramar e ilustrar, así como también los conocimientos básicos para las artes publicitarias. Debido a la trascendencia de su arte es convocado para ilustrar el suplemento educativo ABC del diario Última Hora de Lima. En 1973 crea un personaje llamado Novac para el diario La Prensa y simultáneamente se convierte en el principal ilustrador de su Suplemento dominical. También ilustra una gran variedad de artículos para las revistas Siete Días e Imagen. Es contratado para dibujar algunas historietas de la revista de ciencia ficción y fantasía Lo Insólito. Más adelante es convocado por Carlos Sánchez Luna Victoria para hacer historietas cortas para el suplemento El tío Carlitos de la revista política $X$ (1976). En su afán de impulsar la historieta peruana se une a otros jóvenes dibujantes como Roberto Castro, Jorge Irey, Dionisio y Antonio Torres, Luis Salinas, entre otros y publican Fantazine, un cómic de relatos de terror y misterio que a pesar de su impecable edición sólo duró dos números debido a la coyuntura política de esos años" (Isla Rocha).

10 Consúltese: Fernando Franco, "Los dibujantes peruanos en la revista 7 Días del Perú y del Mundo. En: $<$ http://blogs.peru21.pe/comics21/2012/10/los-dibujantes-peruanos-en-la.html>. 
pueden tener el mismo fin. Entonces, la destrucción del planeta sirve de espejo para el propio mundo de Novac, quien recuerda que sólo tras la destrucción de su planeta inicia su carrera como custodio espacial.

El mundo al que llega Novac tiene animales prehistóricos semejantes al de los terrícolas, son, por lo tanto, exodinosaurios. El progreso de toda civilización humana y alienígena parece concentrarse en dos grandes momentos: lo bárbaro y salvaje del mundo primitivo, y lo moderno y tecnológico de la civilización. Si bien la autodestrucción es implícita, hay una continuidad cíclica que amenaza a la especie. De otro lado, estos mundos futuros proyectados como fantasías prehistóricas, no hay progreso propiamente sino un retorno al pasado, lo que genera una amenaza. Es decir, no se produce el encuentro con civilizaciones superiores sino que estas se encuentran ya en un estado posapocalíptico con el consiguiente retorno a las formas humanas primitivas conocidas.

En ese planeta hay una mujer joven y bella en peligro, amenazada por un monstruo. Novac logra destruirlo y rescatar a la mujer. Para mimetizarse con esa realidad se confecciona un traje acorde con ese estado primitivo. En ese otro mundo la ciencia y la tecnología se enfrentan también a las pasiones naturales como el amor. Ella, Dazia, tras recuperar la conciencia le informa que fue echada al Valle de los monstruos por Sarrio (que fonéticamente remite a "Saurio", reptiles extintos) el tirano del planeta, quien ejerce su poder y dominio sobre los pueblos pacíficos. Sarrio, sádico y asesino de gran poder hipnótico, es el mal supremo al que se enfrentará Novac (que remite a "Nova", estrella pequeña y brillante producto de una explosión) configurado como el héroe salvador no sólo de Dazia sino también de la comunidad y del planeta. Dazia será el objeto de deseo tanto de Novac como de Sarrio.

Uno de los esbirros de Sarrio, de nombre Nekar (juego de sílabas invertidas: karne) se enfrenta a Novac. En la lucha se pone de relieve la fuerza física, y Dazia es un sujeto pasivo que observa las hazañas del héroe. Es una representación estereotípica de la mujer. Incluso, luego de ser salvada por segunda vez, su amor por él crece, lo que la motiva a besarle. Mientras retornan a la comunidad de Orm en busca de Zileb, padre de Dazia, las imágenes de la naturaleza promueven estos afectos y pasiones. Ya en la comunidad, Novac es informado de Sarrio, el Hijo del Mal. Se desprende que el mal es genético, pero en ese futuro el mal puede corregirse mediante la medicina. Sarrio posee un poder hipnótico que permite dominar y subyugar. Para combatir ese poder Novac trae de su nave el Rememorizador (REM-10) una pistola-aparato cuyo rayo permite volver a la realidad a aquellos que no tienen conciencia de sus actos o están dominados por Sarrio. Se trata de una limpieza ideológica, que permite el control del sujeto. Así, Novac va limpiando mentalmente uno a uno del poder de Sarrio. Al verse disminuido en número pretende dominar a Novac, mientras en una experiencia psicodélica Novac transita mentalmente por diferentes tiempos y lucha por la autoconciencia. Sólo Dazia logrará salvar a Novac al golpear a Sarrio, antes de que aquel pierda el sentido, agotado 
por la lucha mental. Vuelto en sí, Novac lleva a Sarrio hasta su nave espacial y ahí, en medio de la sorpresa de Sarrio por la visión de los comandos de la nave, es decir, de la tecnología, es sometido en el quirófano espacial, mientras una luz roja va anulando las células causantes del mal. Finalmente logra limpiarlo de los genes que promueven acciones negativas y retorna con él al planeta (situación similar a La naranja mecánica de Kubrick). Tras el reencuentro con Dazia, Novac recibe el llamado de la nave para otra misión, por lo que se despide de Dazia y se va transmaterializándose hacia la nave (teletransportándose hacia la nave desde la superficie del planeta). Ya en la nave, le informan el pedido de auxilio del planeta Xelton de la galaxia A7. Mientras Novac se prepara en una cámara de hibernación para el largo viaje, va recordando a Dazia, mientras una voz en off se pregunta por lo que le depara el futuro al héroe en este nuevo planeta. Con esta entrega se cierra la primera serie de Novac, ya que luego de algunas entregas más, la serie se verá interrumpida lo que coincidirá semanas después con la desaparición del suplemento.

Si bien Novac está ubicado en un mundo primitivo, contextualmente pertenece a una serie de superhéroes maduros de ciencia ficción. A nivel psicológico tiene mayor complejidad, por ejemplo en la vacilación entre el deber militar y el amor por Dazia. Sarrio encarna la ambición por el poder para gobernar, su poder mental natural se enfrenta a la ciencia. En ese enfrentamiento es vencido. Un subtexto sería que Novac al configurarse como salvador, y liberador, encarna la figura de los EE.UU. (así ha sido su rol al entrometerse históricamente en conflictos políticos ajenos, bajo el lema de la defensa de la libertad y democracia), pero, de otro lado, no tiene como objetivo dominarlos bajo otras formas, sino que Novac busca una homogenización, que todos sean iguales, acaso se trata entonces de una pretensión totalmente utópica, pero es una alternativa imaginaria.

\section{ZARKHAN DE RoBerto CASTRO}

Zarkhan $^{11}$ fue dibujada por Roberto Castro (Lima, 1955), actualmente radicado en

11 Sobre el origen de Zarkhan, el autor lo recuerda así: “[...] estaba trabajando en el diario Correo y Carlos Roose, Cayo Pinto y yo propusimos crear una página que llevara tiras cómicas, Crose de hecho tenía una gran trayectoria y contaba con muchísimos personajes creados por él, Cayo Pinto igual, por lo que yo tenía que conseguir crear uno rápidamente; lo primero que se me ocurrió por sugerencia de Crose, fue de un personaje con las características de Tarzán, bueno, dije ya hay muy malas imitaciones de Tarzán en las historietas y yo vendría a engrosar esas filas, aunque me gustó el sonido de Tarzán y se me ocurrió juntar dos nombres de emperadores ... el ZAR y el KHAN y así quedó el nombre compuesto, también pensé en un niño, hijo de una larga dinastía de sabios gobernantes quien su planeta es aniquilado por una horda invasora, la única opción de ellos es escapar del planeta a bordo de una nave imperial en cuyo interior se encuentran las más prominentes mentes del planeta, la nave es atacada y se defiende, con mucho esfuerzo logra derrotar a sus agresores no sin quedar seriamente dañada y sin posibilidades de escape, la única 
México. Apareció entre el 7 de marzo y 26 de julio de 1978 en el diario Correo de Lima, en entregas discontinuas, de lunes a sábado ${ }^{12}$. Las influencias de Castro son diversas, dado su contacto con el mundo académico y con la cultura de masas:

[...] los comics editados por La prensa y Novaro tales como Titanes Planetarios, Mi gran aventura, Cuatro fantásticos, Spiderman, Batman, Superman, seguí mucho la obra de Neal Adams, Alex Raymond, Milton Cannif [...] mis influencias dentro de la pintura más fuertes siempre serán, Velásquez, Rembrandt, Mariano Fortuny, Dalí y en especial Rubens [...] (Honores, "Entrevista a Roberto Castro")

En 1975 Castro fundó la revista Fantazine (revista de humor satírico) y luego otra publicación Los inmortales, en 1977 junto a Dionisio Torres, Antonio Torres, José Caycho y Jorge Monterrey (La Oroya, 1948), con una historia titulada Zor de los Dinosaurios. En esos años fue colaborador de las revistas limeñas Gente, Suácate, Correo y El periodiquito, dirigida esta última por Luis Felipe Angell (1926-2004), en los que Castro dibujaba "caricaturas políticas contra el régimen militar de mi país". En los ochenta desarrollará una carrera en México, ilustrando publicaciones como Novelas Inmortales, Artes marciales y posteriormente Star Trek para la DC Comics y Conan de Marvel, las dos editoriales norteamericanas más importantes, poderosas e influyentes del comic.

La primera imagen de Zarkhan es la de una nave absorbida por el sol. Ante la inminente destrucción, el capitán ordena que su esposa sea evacuada en el módulo de emergencia. Sin embargo, ella se sacrifica para que su hijo Zarkhan, sea salvado, lo que tiene notables similitudes con el origen de Superman. Curiosamente Zarkhan lleva un traje espacial con las iniciales "F.A.P.", lo cual denotaría la procedencia de esta tripulación (Fuerza Aérea del Perú) cuyas acciones transcurren en el futuro. El padre agrega que

esperanza del planeta radica ahora el inocente niño que juega dentro de la nave con su robot nodriza Bugui ... es Zarkhan. El collar que lleva al cuello contiene todos los conocimientos del planeta y la posibilidad de reconstruirlo (increíble que se me ocurriera esto, en el setenta y ocho se desconocían los microchips y los usb) se alista la única nave de escape que queda para lanzar a Zarkhan en trayectoria a un cercano planeta, pero la nave ya carece de energía suficiente para lograr el viaje, la única oportunidad es la de activar el mecanismo de auto destrucción de la nave nodriza y así lograr el impulso inicial que lleve el pequeño modulo hacia el planeta el costo es la vida de la tripulación, una tremenda explosión sacude la paz del espacio y la pequeña nave es impulsada al vacio por la fuerza de la explosión rumbo al planeta donde se encontrará con su destino" (Honores, "Entrevista a Roberto Castro").

${ }^{12}$ El autor recuerda así sus inicios: “[...] entré a estudiar diseño publicitario y artes plásticas en la Escuela de Arte 'Adelina Concha' iba allí como alumno libre pues no llegaba a la edad para el ingreso oficial, combinaba esto con los estudios de colegio y de idiomas casi todas las noches, al cumplir los 17 gané un concurso para la plaza de dibujante en el diario peruano Última Hora ilustrando una tira diaria de la novela del autor peruano López Albújar titulada Matalaché [luego retomé] clases en la Escuela Nacional Superior [Autónoma] de Bellas Artes, y [me encerré] allí 6 añitos estudiando todo en lo que nunca iba a trabajar los compañeros puristas del arte me miraban como un sacrílego de las artes [...]". Consúltese: "Roberto Castro. Entrevista". En: <http://club-batman.es.tl/ENTREVISTADOS.htm>. 
la computadora lo llevará a Delfos, descrito como "un planeta muy similar al nuestro" (29 marzo). Esta segunda mención es importante por cuanto mucha producción de este género, para evitar la censura, tuvo que ubicar sus historias en espacios y tiempos indeterminados, pero que hacían alusión a una realidad sociohistórica concreta, vista desde códigos y formas de la ciencia ficción.

El módulo cae en un "primitivo planeta selvático" (31 marzo) y tanto Bugui (el robot niñera) como Zarkhan se ven en peligro por la aparición de una bestia gigante con forma de serpiente (boa). Para James Hall la serpiente es "símbolo del mal y sinónimo bíblico de Satanás" (221), por lo que este planeta se construiría como una especie de "infierno". Oportunamente irrumpe en la escena Gurlak, personaje que a pesar de su inteligencia primitiva, logra vencer a la "ferocidad salvaje" (4 abril) al arrancarle el cuerno a la serpiente, que le daba poder al ofidio. Tras este hecho queda establecida la amistad entre el niño, la bestia y la computadora, asumidos como tres posibles estadios de la evolución.

Veinte años después, Zarkhan es ya adulto e ignora lo que el destino le depara, lo cual reafirma ideológicamente un universo regido por los dioses y no por el hombre en sí y sus propias acciones. El villano Gorgo y su ayudante Igor, observan desde su castillo a los personajes y determinan que son los ideales para ser parte de "juego" mortal. La imagen del castillo, además de cierta reminiscencia gótica simboliza el poder arcaico y conservador, encarnado en Gorgo. Zarkhan intuye el peligro pero no lo puede determinar con exactitud, al igual que Bugui, quien no capta nada. Por un error, los tres son teletransportados al mundo de Gorgo, quien les anuncia que deben pasar por tres pruebas.

La primera prueba mide destreza mental con Senzor, maestro de ajedrez cósmico (13 abril), Bugui se las ingenia para desconcentrar a Senzor a partir de jugadas ilógicas, lo que permitirá finalmente vencer. Ante la pregunta de Gurlak sobre el por qué de la existencia de seres malvados, Zarkhan responde "Es la ley del eterno dualismo entre el bien y el mal" (21 de abril). En el comic ambas fuerzas operan y se manifiestan de modo claro a partir de oposiciones: los malvados tienen rasgos monstruosos y son encarnaciones del mal, mientras que el héroe coincide con el estereotipo del héroe clásico norteamericano: rubio, de gran fuerza y musculatura física, y valores positivos, que recuerdan al Flash Gordon dibujado por Alex Raymond y Al Williamson y que influenciaron a una serie de dibujantes peruanos, como Castro, Monterrey o Jorge Bernuy. Pero volviendo al relato, Gorgo los obliga a participar de la segunda prueba: luchar contra dos bestias: un grifo y una masa informe. Zarkhan responde "Le enseñaremos a este dictador lo que es la libertad". Además de erigirse la libertad como un valor importante dentro de la secuencia narrada, consideramos que es también una sutil alusión al ambiente opresivo y de control del gobierno militar, que se ve refractado en la cita. Mientras tanto en otro espacio Gorgo e Igor discuten sobre la necesidad de esclavizar a la raza nativa del planeta 
para mantener la extracción del precioso metal radioactivo y así mantener el dominio sobre otros planetas. Zarkhan logra vencer al grifo y ayuda a Gurlak con el monstruo informe. Los personajes logran escapar tras un descuido de Igor, quien corta la barrera magnética. Los personajes llegan donde la raza de los caricatos, seres de apariencia infantil a quienes pretende esclavizar Gorgo. Ellos los llevan hasta la presencia de su reina Selen. Zarkhan al verla quedará enamorado. Los caricatos y Selen habitan en una ciudad subterránea.

Gorgo, enfurecido lanzará a sus temibles dlaculaz, seres de formas vampíricas, para que los atrapen. Frente al inminente ataque, Zarkhan asume el liderazgo para enfrentarse a las fuerzas del mal. Tras un alud, Zarkhan cree haber vencido a los temibles dlaculaz. Sin embargo, estos renacen de entre los escombros. El pueblo selenita celebra esta victoria ilusoria, mientras el amor entre Zarkhan y la reina Selen crece. Estos son atrapados por los dlaculaz. Gurlak y Bugui salen en su búsqueda. Ellos encuentran a Zarkhan atado a un árbol a merced de los temibles seres denominados como "gilas", especie de plantas carnívoras que salen luego del atardecer. Bugui señala: "Odio la violencia pero [esta situación] necesita de ella” (5 julio). Gurlak y Bugui logran rescatar a Zarkhan. En otro espacio Gorgo intenta convencer a Selen de que la unión entre ambos sería mejor para tener el poder absoluto. En esa entrega, Roberto Castro introduce un mensaje personal en clave: para "V" (9 julio).

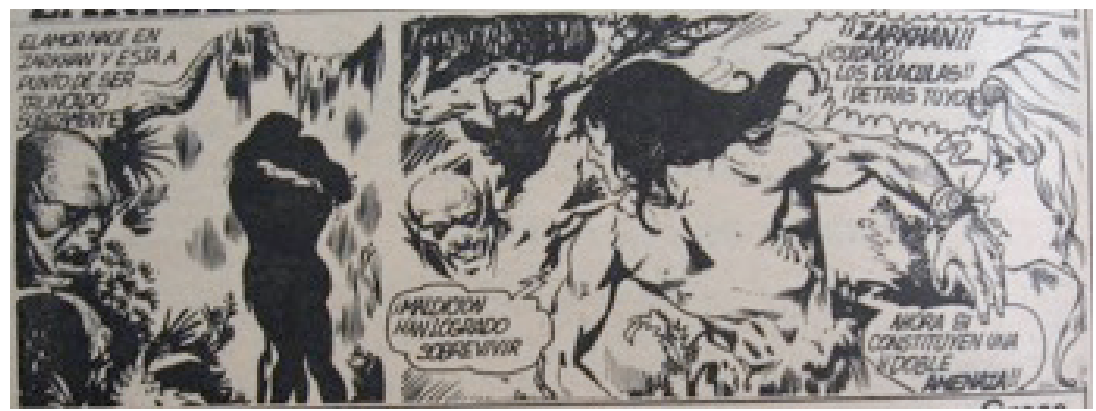

Zarkhan se enfrenta a los dlaculaz

Zarkhan recibe el apoyo de los caricatos en su lucha contra Gorgo. Su sirviente Igor, tras su vacilación constante sobre los actos condenables de Gorgo decide ir en busca de ayuda. Va en busca de Asgarot, quien según la demonología, es el gran duque del infierno. Asgarot le ofrece su ayuda porque ve en él un atisbo de verdad. En otro espacio y ante la negativa de Selen de aceptar la unión, ella está a punto de ser arrojada contra seres esclavizados, que en palabras de Gorgo "son los residuos deformados de lo que fue un pueblo como el tuyo... gracias a las guerras esta gente se volvió completamente 
loca" (19 julio). Se trata de seres caníbales. Frente a la proximidad y el riesgo de ser convertida en víctima irrumpe Zarkhan, quien logra salvar a su amada. De otro lado Asgarot también aparece en escena, pero no logra apaciguar a su discípulo Gorgo. Asgarot le dice a Gorgo: "[... ] te pido que te arrepientas ahora de esto porque cuando mi poder se desate será muy tarde aún para tu alma" (27 julio). Tras ello, fuerzas cósmicas van destruyendo el escenario de Gorgo, mientras Selen y Zarkhan tratan de ponerse a buen recaudo. En un momento una avalancha cae sobre Asgarot, pero Igor da su vida por salvar la de aquél. Gorgo, quien se encuentra huyendo, es finalmente capturado. A pesar del orden establecido en la ciudad selenita, llega la triste noticia: los cuerpos de Gurlak, Bugui y Zarkhan se desintegrarán para retornar a su planeta de origen de donde fueron sacados. Ello causa escenas de despedida dolorosa para Zarkhan y Selen. Finalmente los personajes retornan a Delfos.

Aquí concluye propiamente la historia de Zarkhan. Sin embargo, la condición del artista real se verá refractada en dos entregas más, pues a pesar de anunciarse otra fabulosa aventura en la serie, el propio Castro se dibuja a sí mismo. El artista se verá perseguido por sus acreedores a quienes toma por admiradores. Hay una coincidencia entre la carencia de ideas y el no pago, en un cartel se lee "[mes de] Julio ¿Cuando pagan Zarkhan?". El segundo cuadro destaca un letrero que dice "México o morir en el camino" (que anuncia la decisión real del artista de radicar en México, cuyo soporte editorial resultaba a todas luces más moderno que el peruano); en el tercer cuadro: "La austeridad es buena: consúmala (mentira)", crítica sutil a la falsa economía del poder militar de turno, pues las expectativas sociales eran otras. Ante la pregunta sobre la relación entre Zarkhan y la dictadura de los setenta, el autor responde:

\begin{abstract}
Zarkhan y los años de dictadura militar tienen mucha relación pues nació dentro de un estado sin garantías ni derechos, fue a la par que trabajaba en revistas políticas y con críticas directas, una manera de mostrar el panorama social desde otro contexto más sencillo a través de una historia paralela, aunque el fin de la historieta no era en sí la de hacer crítica social no podía estar alejada de los sucesos de aquel tiempo y quería ejemplificarla con historias que contaran problemas que nunca dejarían de acontecer en una sociedad, hasta que se encuentre el sistema perfecto de gobierno, que es casi una utopía [...] el poder en manos de un gobernante sin elección ni control del pueblo engendra monstruos y son peores estos [...] de los que aparecen en los comics o películas. (Honores, "Entrevista a Roberto Castro")
\end{abstract}

Llama poderosamente la atención la conciencia del autor sobre el marco social en el que inscribe su obra, con lo cual, quedan comprobadas las interferencias e imbricaciones entre la obra de arte y la época dominante. 


\section{Yungay 70 De Jorge Monterrey}

Yungay 70 fue dibujada por Jorge Monterrey (La Oroya, 1948). Se inició dibujando la historia de los huancas en Correo, sucursal de Huancayo en 1970. En los sesentas fue historietista del suplemento "Jaimito" de Correo; además de realizar adaptaciones de obras como 20,000 leguas de viaje submarino de Julio Verne (1828-1905) o "Ushanan Jampi", de Enrique López Albújar (1872-1966), entro otros. Yungay 70, ${ }^{13}$ fue publicado en Correo en 1978, entre el 1 de mayo y el 24 de julio en entregas discontinuas, de lunes a sábado.

Yungay 70 es la historia de un hombre del planeta Tierra que desde el futuro viaja al pasado sin saberlo - al modo de El planeta de los simios-, pero con la intención de evitar un desastre, a diferencia de comic clásicos (como Flash Gordon o Buck Rogers) en donde seres humanos viajan a planetas nuevos. Yungay 70 tiene como punto de partida el trágico suceso acaecido en 1970: el terremoto en Huaraz. El desprendimiento del Huascarán sepultó a toda una comunidad del pueblo andino. El narrador destaca el carácter épico del pueblo peruano que se sobrepuso a tal acontecimiento, a su vez, opondrá claramente la fuerza de la naturaleza frente al hombre y su ciencia que intenta controlarla.

Un grupo de pacifistas extraterrestres comandados por Sor-el, llegan desde su lejano planeta a la tierra, con un propósito meramente científico: evitar el desastre de Yungay, provocado por las pruebas nucleares en el Atolón de Mururoa, en las costas del Océano Pacífico, que debilitan ciertas fallas geográficas. Los tripulantes de la nave comentan dos de los vicios humanos: su carácter bélico y su egoísmo e indiferencia frente a los más necesitados. Los pacifistas determinan científicamente a Yungay como centro del desastre y se dirigen hacia este lugar. El doctor Rang-el es también parte de la tripulación oficial. La nave auxiliar abandona la nave madre, en medio de comentarios sobre la propia autodestrucción humana. Recordemos que son los años de la guerra fría, en donde la posibilidad de un desastre nuclear a escala mundial era totalmente posible.

La nave es vista como una estrella fugaz por los pobladores. Uno de ellos comenta que es signo de mal agüero (6 mayo). Al día siguiente hay un sol inusual. Marcela aparece en escena: es una joven lugareña que decide ir a tomar un baño en el río. Sor-el al verla en el río queda prendado de su belleza. Sor-el agrega que mientras los países

13 En 1976 Monterrey afirmaba en una entrevista local que "Resultaría [...] absurdo crear historias que fueran calco o copia de las que han sido prohibidas por alienantes. No sería lógico dar vida, por ejemplo, a un Batman peruano porque ello significaría justamente recorrer el camino que queremos evitar" (7). Respecto a la pregunta sobre de dónde sacar a los personajes, agregaba que de “[...] nuestra historia, nuestro folklore, nuestras leyendas [que] constituyen una fuente de inspiración inagotable, hoy desaprovechada [...] Lancémonos a animar personajes que respondan a nuestra idiosincrasia y a nuestro sentir" (7). Yungay 70 es fruto de esa posición estético-ideológica. 
pobres [como el Perú] luchan por subsistir, los países del Primer Mundo construyen armas mortíferas. Aquí se manifiesta el discurso pacifista, pero también una conciencia de la condición periférica del país, que se encuentra al margen de las políticas del Primer Mundo. Marcela se dejará guiar por su nuevo amigo, quien le enseñará la historia de su mundo y su misión. En una pantalla, Sor-el (cuyo nombre remite a Jor-el, padre de Superman), le enseña la historia de su planeta llamado Bermómedas. En el pasado existieron también grandes potencias económicas enfrentadas mutuamente, al punto en que el planeta, luego de la guerra se convertiría en una bola de fuego, causando caos y destrucción. Los sobrevivientes se vieron en la necesidad de vivir bajo tierra, hasta que se disiparan las nubes radioactivas. Una nueva generación salió a la superficie. Era un nuevo mundo y la esperanza renacía, pues tras el desastre de la guerra se formó una sola nación que luchó contra la pobreza y pregonó la paz que "El Supremo", ordenara. "El Supremo" sería el equivalente al Dios terrícola, nominado de diversos modos por distintas religiones. Para Sor-el, "El Supremo" es una suerte de dios panteísta pues además de estar en el cielo, en la tierra, en el aire, está en las flores. Sor-el le expresa su amor a Marcela y luego de ello se produce un encuentro amoroso entre ambos ocultado precisamente por la naturaleza como único testigo. En cierta medida esta acción erótica se contrapone al amor puro que motiva las acciones de personajes en historietas más conservadoras, cuya visión tradicional es la de superar los conflictos sociales por medio de un amor abstracto y de buen burgués, asexuado. Por el contrario, hay un cierto liberalismo sexual. Al retornar a casa, Marcela se ve enfrentada a sus padres: la madre está preocupada por su ausencia, pero el padre más opresivo no cree en la explicación de la demora. Le informa que Rosendo, su "prometido" (pues ambas familias han acordado el matrimonio) la estuvo buscando. Marcela llora de no poder decirles la verdad: la misión de Sor-el. El estereotipo de la mujer es el del sujeto controlado y ubicado en el espacio cerrado, que niega la aventura.

El posterior encuentro entre Rosendo y Marcela es melodramático: Rosendo amenaza a Marcela con matarla pues prefiere verla muerta antes que sea de otro. Marcela da por terminada la relación. Sin embargo la voluntad de la mujer no es tomada en cuenta, pues Rosendo se despide del padre de Marcela diciendo que volverá pronto por ella (29 mayo). Tras ello empieza a llover, como un signo que adelanta los hechos. Tras cinco días de encierro, Marcela va en busca de Sor-el. Las citas amorosas se suceden, pero son descubiertas por Rosendo, quien piensa sólo en la venganza por la traición. Sor-el le comunica a Marcela que salvarán a la población así ello implique darle a conocer al mundo su existencia, anunciarán la evacuación por medio de un parlante superpotente.

Un diálogo entre el doctor Rang-el y el comandante Sor-el, anuncia que éste último piensa llevarse consigo a Marcela y establecerse en Bermómedas, pues quiere dejar de ser un trotamundos espacial (9 junio). Cuando detectan los primeros movimientos que darán paso a la catástrofe, Sor-el se apresta a poner en práctica el plan de salvación, 
pero es impedido por el propio doctor Rang-el, quien le dice que "El destino del hombre tiene que cumplirse" (19 junio). El doctor agrega que Sor-el tiene que morir, pues si no su futuro cambiaría. El capitán elimina al doctor y se pone del lado de Sor-el diciendo que "No soy partidario de recibir órdenes ciegamente sin entender razones" (22 junio). Esta alusión podría leerse como una crítica sutil al orden militar, rígido y vertical. Los extraterrestres se aprestan a iniciar el plan para evitar el desastre.

Sor-el se reúne con Marcela para salvarla, pero irrumpe Rosendo en la escena. Este toma la iniciativa y está a punto de lograr su "venganza", cuando inicia el terremoto y cae al interior de la tierra cuando ésta se abre. Marcela y Sor-el apenas logran ponerse a salvo gracias a la nave. Mientras, el pueblo de Yungay es sorprendido y casi todos mueren. El narrador agrega que para estos seres era el fin del mundo (29 junio).

Tras el retorno a la nave madre y de regreso a su planeta de origen, Bermómedas (que significa "Nueva vida") reciben el llamado del Superior, quien les revela la verdadera misión completándoles su propia historia: luego de las guerras y ante el temor a que se formara nuevamente en sus habitantes el carácter bélico, se borró de todo recuerdo del pasado de las mentes de los personajes al igual que en sus computadoras. Se revela que en el pasado ese planeta se llamaba Tierra. Sólo aquí se descubre que Sor-el y su tripulación vienen del futuro y fueron enviados al pasado, y a la Tierra como si fuera un nuevo planeta por pacificar, pero ese plan fracasa por el enamoramiento de Sor-el por Marcela. Una escena de horror se abre paso: Sor-el ve cómo su amada se desintegra frente a sus ojos, al modo de "El caso del señor Valdemar" de Poe. El único modo de traerla a la vida es volviendo al pasado, pero, al tratar de cambiar el rumbo, una nube de meteoritos terminará por destruir a la nave y a toda su tripulación. El final de la narración plantea la situación de si el hombre hace su destino o si está determinado de antemano. Sor-el y su tripulación ignoraban que venían del futuro y por ello no podían cambiar ese episodio trágico en Yungay.

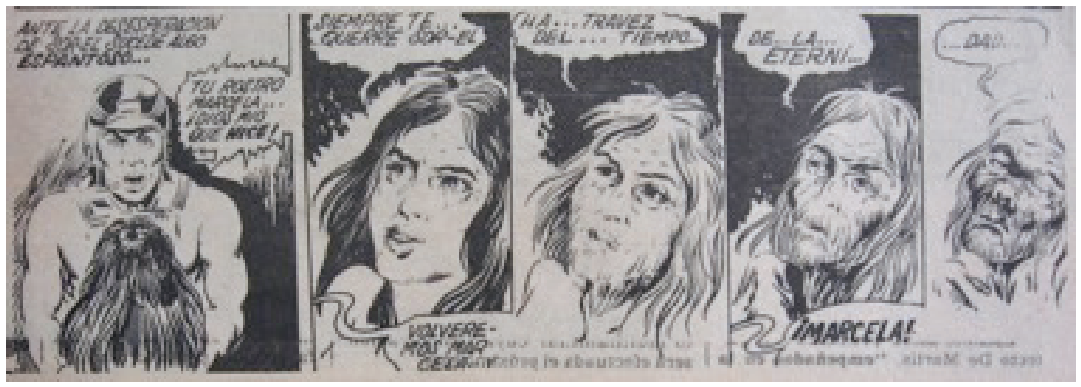

Desmaterialización de Marcela 
Esta historieta cuestiona en última instancia nuestro concepto de civilización (Ruiz Zapatero 286), al plantear que nuestro presente/futuro, lo que consideramos moderno y en perspectiva de progreso, es pasado para Sor-el, y por lo tanto en sentido metafórico "prehistórico". Yungay 70 dialoga con el tópico del viaje en el tiempo de Wells. Pero, además de ello, se remarca el espacio peruano como subdesarrollado, periférico frente al primer mundo y que incluso somos víctimas de su armamentismo desmedido, pues plantea la relación entre las pruebas nucleares y el desastre en Yungay. ${ }^{14}$

Podemos concluir que la principal influencia en la historieta peruana de ciencia ficción es la industria norteamericana, expresada en productos como Flash Gordon, Tarzán y Superman, entre 1950 y 1980, en donde el héroe posee rasgos univalentes, poca densidad psicológica y es encarnación absoluta del bien frente al mal, encarnado generalmente en la figura de un tirano que pretende dominar el planeta. La influencia norteamericana fue posible por la difusión de sus productos en distintos medios de prensa limeños, además del impacto del cine. Es decir, esta producción está asociada a la cultura de masas. A nivel literario son claras las influencias de La máquina del tiempo y La guerra de los mundos de H. G. Wells (1866-1946), junto con Viaje a la luna y Viaje al centro de la tierra de Verne. En todas subyace el tópico de la invasión, que se vio reforzada por la denominada Guerra Fría. El futuro que representan estas historietas subyace la idea de la destrucción del planeta producto de la guerra atómica con el consiguiente retorno a un orden primitivo. Ese miedo real se reescribe en diversas situaciones. Se trata de una tensión entre la barbarie y la civilización pero a nivel global, por ello son representaciones discursivas que recogen miedos reales de la sociedad y proyectan mundos distópicos.

\footnotetext{
${ }^{14}$ En Zarkhan y Yungay 70, la mujer asume su rol estereotípico frágil, pura y sumisa; frente al hombre, con atributos como fuerza poder y virilidad. La inteligencia es más clara en Marcela, pues Selen de Zarkhan, cumple con la mujer bella, gobernante de la nación. En ambos casos vemos cómo lo social termina por imponerse. En Zarkhan la realidad es más brutal al punto que las tensiones entre el artista y su obra terminarán por anular y expulsar a este del circuito limeño, para emigrar a la industria mexicana, más sólida; por ello, el vuelco cómico de la serie en las dos últimas entregas, además de la ya señala interrelación entre arte y política. En Yungay 70, la realidad de la guerra fría es latente y a través de este juego temporal, podemos atisbar un futuro negativo para la humanidad. Un elemento más liga a ambas historietas: ambos personajes carecen de los superpoderes típicos, se destacan en cambio, sobre todo por sus razonamientos, esquemático en Zarkhan y con perspectiva humanista en Sor-el. Como señalaba Gonzalo Ruiz Zapatero, respecto del tránsito de una historieta de ciencia ficción a otra de fantasía que explora el pasado, concluye señalando que parece "más fácil reinventar el pasado que modificar el futuro" (299).
} 
BiBLIOGRAFÍA

Franco, Fernando. "Los dibujantes peruanos en la revista 7 Días del Perú y del Mundo. 11 oct. 2012. <http://blogs.peru21.pe/comics21/2012/10/los-dibujantes-peruanosen-la.html>

Hall, James. Diccionario de temas y símbolos artísticos. Madrid: Alianza, 2003.

Honores, Elton. "Entrevista a Rubén Osorio”. Inédito, 2013 "Entrevista a Roberto Castro". Inédito, 2010

Isla Rocha, Martín. "Recordando a Jorge Bernuy". Mundocomics. 24 oct. 2011. <http:// mundocomics2011.blogspot.com/2011/10/recordando-al-dibujante-peruano.html $>$.

Kakalios, James. La fisica de los superhéroes. Madrid: Ma non troppo, 2006.

Ledgard, Melvin De Supercholo a Teodosio: historietas peruanas de los sesentas y setentas. Lima: ICPNA, 2004.

Osorio, Rubén. "La cadena de oro". Revista Última Hora. 1952.

Ruiz Zapatero, Gonzalo. "Héroes de piedra en papel: la prehistoria en el cómic". Complutum VIII (1997): 285-310.

Sagástegui, Carla. La historieta peruana. Los primeros 80 años (1887-1967). Lima: ICPNA, 2003.

Saravia Mendes, María Regina. El papel educativo de los comics infantiles. Tesis de Doctorado. Universitat Autónoma de Barcelona, 1992. Barcelona: Bellaterra, 1992.

Salvo, Daniel. "José B. Adolph y la Edad de Oro de la ciencia ficción peruana". Tinta Expresa Revista de Literatura IV (2010): 133-143. 